\title{
A PESCA COLETIVA COM TIMBÓ PRATICADA PELOS IKPENG: ENSINAMENTOS DESSA RELAÇÃO RESPEITOSA COM A NATUREZA
}

\author{
Kavisgo Txicão ${ }^{1}$ \\ Marcelo Franco Leão ${ }^{2}$
}

\begin{abstract}
RESUMO
A prática da pesca artesanal entre os povos indígenas é bem antiga e importante. O objetivo da pesquisa é relatar a prática dessa pesca realizada pelos Ikpeng (Mato Grosso) com intuito de refletir a relação respeitosa deste povo com o meio ambiente. O estudo caracteriza-se como etnográfico, cuja abordagem é qualitativa, e foi desenvolvido nos anos de 2014 e 2015. Como instrumentos de produção de informações utilizou-se as observações a campo, o registro no diário de bordo e algumas entrevistas com pessoas da comunidade, por meio de suas memórias culturais. Os resultados permitiram compreender o conhecimento empírico que o povo lkpeng têm sobre a natureza, além de ressaltar que a prática da pesca não é um crime ambiental, mas sim uma ação racional e respeitosa com a natureza para sua sobrevivência.
\end{abstract}

Palavras-chave: Pesca com timbó. Prática cultural. Educação Ambiental.

\begin{abstract}
The practice of artisanal fishing among the indigenous peoples is ancient and important. The purpose of the research is to report the practice of this type of fishing the Ikpeng (Mato Grosso) perform with aims to reflect upon the respectful relation of that people with the environment. The study is characterized as ethnographic, of a qualitative approach, that was developed in 2014 and 2015. As instruments of information production it was used observations, log book records and some interviews with people from the community, through their cultural memories. The results allowed to comprehend the empirical knowledge the Ikpeng people have of nature, in addition to pointing out that the practice of fishing is not an environmental crime, but yes a rational action that is respectful with nature for their survival.
\end{abstract}

Keywords: Fishing with timbó. Cultural practice. Environmental education.

\footnotetext{
${ }^{1}$ Professor na Escola Indígena Central Estadual Ikpeng, município de Feliz Natal-MT. E-mail: kawiago25@gmail.com

${ }^{2}$ Doutorado em Educação em Ciências (UFRGS). E-mail: marcelo.leao@cfs.ifmt.edu.br
} 


\section{RESUMEN}

La pesca artesanal entre los pueblos indígenas es una práctica muy antigua e importante. Esa investigación tuvo el objetivo relatar la práctica de esa pesca realizada por los Ikpeng (Mato Grosso) con el propósito de expresar la relación armónica de este pueblo con el medio ambiente. Ese estudio es etnográfico, cuyo enfoque es cualitativo, y fue desarrollado en los años 2014 y 2015 . Para obtener los datos se utilizaron las observaciones a campo, el registro en diario de bordo y algunas entrevistas con las personas que tienen el dominio amplio cultural. Los resultados permitieron comprender el conocimiento empírico que el pueblo Ikpeng tiene de la naturaleza, aún resaltar que la práctica de pesca no es un crimen ambiental, pues si una acción racional y respetuosa con la naturaleza para su supervivencia.

Palabras clave: Pesca con timbó. Práctica cultural. Educación ambiental.

\section{INTRODUÇÃO}

A mãe natureza é a fonte de riqueza mais importante que existe na visão de toda a população indígena. Ela é a fonte para a sobrevivência, não só fisiológica como também cultural, pois é dela que são retirados os elementos utilizados na alimentação, moradia e utensílios, bem como, os utilizados para a realização dos rituais. Os indígenas acreditam que as plantas, aves, animais silvestres, pedra, lagos, rios e tudo o que existe na natureza tem seus donos espirituais (SÁ; SILVA, 2017).

Albuquerque, Leite e Castro (2016), discorrem sobre as consequências da globalização na cultura do povo indígena Krahô, estabelecido na região nordeste do estado de Tocantins. Os autores alertam sobre a importância de preservar os saberes tradicionais, manifestados em ritos, danças, mitos, costumes, enfim, fortalecer a identidade do indígena para que não sucumba pela dominação cultural eurocêntrica.

A cultura indígena não pode ser descaracterizada. Aos poucos a língua portuguesa vem sendo inserida na fala do povo lkpeng, as tecnologias também são fonte de preocupação pois está mudando a rotina tradicional da comunidade. Para minimizar esse processo, a escola lkpeng valoriza e incentiva os alunos quanto ao conhecimento tradicional do povo, realizando 
atividades práticas e também incentivando nas pesquisas e participação nas festas (IKPENG, 2010).

O estudo de Sá e Silva (2017) relata as práticas culturais do povo indígena Tentehar, que estão centradas na relação com a natureza. Essa etnia está localizada em Amarante, município pertencente ao estado de Maranhão. O estudo permitiu constatar que esse povo extrai da floresta vários significados para suas práticas cotidianas, ou seja, a natureza ensina lições que influenciam diretamente sua cultura.

Por sua vez, Barbosa et al. (2017), investigaram a relação do povo indígena Paiter Suruí, estabelecido na região amazônica do estado de Mato Grosso, com a natureza nos aspectos sociais, culturais, ambientais e econômicos. Os autores relataram atividades como o artesanato, a coleta e plantio de sementes, a colheita, utilização e comercialização de alimentos. Essas atividades subsidiaram as discussões sobre o cuidado desse povo tradicional com o meio ambiente.

Um aspecto a ser considerado na relação dos indígenas com a natureza é o fato de que há muito tempo os povos tradicionais praticam a caça e pesca como meio de sustento das suas famílias (TAPIRAPÉ; LEÃO, 2017). Foi o conhecimento amplo da natureza que permitiu aos indígenas explorarem essa forma de obtenção do alimento. Além disso, muitos povos indígenas têm o peixe como base alimentar.

Nesse sentido, é preciso considerar que existem várias técnicas de pesca utilizadas nas comunidades indígenas. Nesse estudo é abordada uma pesca específica que utiliza o cipó timbó-açu (Sapindácea), chamado pelos Ikpeng de inak. Essa pesca artesanal não é realizada de qualquer maneira, apresenta regras e ritos para não prejudicar os ecossistemas e os seres vivos que dele fazem parte (TAFFAREL, 2010).

No entanto, a pesca com timbó é vista pelo não indígena como um crime ambiental, como uma prática exploratória desenvolvida de qualquer maneira e, por isso, a considera altamente prejudicial ao meio ambiente. Essa visão distorcida precisa ser superada, por isso esse estudo poderá contribuir, no sentido de esclarecer o quão harmoniosa e equilibrada é a pesca praticada pelos Ikpeng, indígenas estabelecidos no Parque Nacional do Xingu em Mato Grosso. 
Além disso, é preciso considerar as orientações da Resolução № 02/2012 que estabelece as Diretrizes Curriculares Nacionais para a Educação Ambiental (BRASIL, 2012). Segundo esse documento oficial, um dos objetivos da Educação Ambiental é o de desenvolver a compreensão sobre as relações que se estabelecem entre o meio ambiente e as práticas sociais, no intuito que esse estudo proporcione novos hábitos de respeito e preservação da sociedade para com a natureza.

Considerando o exposto, o objetivo do estudo é relatar a prática da pesca coletiva com timbó-açu utilizada pelos Ikpeng, com o intuito de refletir a relação harmônica desse povo com o meio ambiente. Essa prática, além de garantir alimentos, envolve importantes aspectos de interação entre homem e natureza, ou seja, esse registro poderá servir para promover reflexões sobre Educação Ambiental na sociedade contemporânea.

Para tanto, foi necessário registrar as técnicas utilizadas por esse povo tradicional, e identificar o potencial educativo dessa prática para as crianças, bem como evidenciar a importância do manejo sustentável dos recursos naturais evidenciando a possibilidade do ser humano viver em harmonia com a natureza.

Cabe ressaltar que o presente texto é baseado no Trabalho de Conclusão de Curso de Licenciatura em Ciências Matemáticas e da Natureza, apresentado pelo autor indígena para a Faculdade Intercultural Indígena da Universidade do Estado de Mato Grosso (UNEMAT), cuja defesa ocorreu no ano de 2016. O intuito desse pesquisador indígena é extrair dos elementos constituintes da cultura lkpeng importantes ensinamentos da ciências da natureza, a exemplo dessa prática coletiva que envolve muitos aspectos possíveis de serem relacionados com a Educação Ambiental.

\section{RELAÇÕES DOS POVOS INDÍGENAS COM A NATUREZA}

O Brasil é considerado o país de maior diversidade cultural do mundo, cada uma dessas culturas é repleta de manifestações como: religião, lendas e línguas diferentes (DIEGUES et al., 1999). São mais de 672 áreas indígenas reconhecidas pelo Estado. Ao todo, vivem nessas áreas, 571 mil índios, de 250 etnias, de um total de 8960 mil índios, e mais de 180 línguas (IBGE, 2010). 
Cada povo tem sua cultura e suas práticas de cunho ecológico, os seus conhecimentos de como lidar com o meio ambiente, como explorar a natureza sem ameaçar a biodiversidade, aprimorando o manejo para consumo familiar com a finalidade de atender suas necessidades. Segundo Taffarel (2010), desde antes da chegada dos europeus no continente, os indígenas vêm adotando práticas sustentáveis em seus territórios, porque, para os povos indígenas, a natureza é considerada um importante patrimônio cultural, com valor na vida de cada indivíduo.

Segundo Baniwa (2006, p. 100), os povos indígenas formaram, ao longo de milhões de anos condições excepcionais, pois: "Sua mentalidade, ecológico-cultural foi se desenvolvendo no processo de sua atividade vital, na relação equilibrada entre cultura tradicional e ecossistemas naturais".

Ainda segundo o autor supracitado, os conhecimentos empíricos espontâneos foram se constituindo em normas de comportamento para 0 usufruto racional da natureza, para sua manutenção e reprodução.

Diegues e colaboradores afirmam que:

\begin{abstract}
Um aspecto relevante das culturas indígenas é a existência de sistema de manejo que os povos têm com recursos naturais que são marcados pelo respeito aos ciclos naturais, ou seja, através de observação de sinais de elementos da natureza e pela sua exploração dentro da capacidade de recuperação das espécies de animais e plantas utilizadas[...]. Na visão dos povos da floresta, rios, lagos, florestas, animais, peixes e todos os seres vivos estão repletos de entes mágicos que castigam os que destroem as florestas e animais (DIEGUES et al., 1999, p. 23-24).
\end{abstract}

O pensamento supracitado é confirmado por Taffarel (2010) que afirma ocorrer entre o povo Ikpeng relações harmoniosas com a natureza, de manejo sustentável, pois só retiram o suficiente para a subsistência, como para alimentação, para construção da moradia e para realização das práticas culturais.

Conforme o pensamento de Baniwa (2006), as populações urbanas têm muito para aprender com os povos tradicionais que vivem de maneira harmônica com a natureza. Em outras palavras, o autor defende que os indígenas respeitam a natureza e, desde suas origens, utilizam somente os recursos necessários para sua manutenção (alimentação, construção de moradia, artesanatos, mantimentos e artefatos). O que é diferente das ações 
praticadas pelo não indígena que considera os recursos naturais como um produto de potencial econômico inesgotável.

Taffarel (2010) ainda complementa afirmando que os indígenas desde criança aprendem a respeitar o meio ambiente e tudo que nele existe. Segundo os pajés Ikpeng, que se comunicam com os seres da natureza, dizem que não pode desrespeitar ou desafiar a força da natureza, porque ela é vingativa, isso para povos indígenas é considerada como uma verdade absoluta.

Ainda seguindo o autor supracitado, a mata é uma espécie de farmácia, de onde retiram vários tipos de remédios, um verdadeiro supermercado de onde se obtém os alimentos, ou ainda como uma loja de construção, que fornece os materiais para construção das casas, além de outros materiais.

\section{AS FORMAS DE PESCA UTILIZADAS PELOS POVOS INDÍGENAS}

A pescaria é uma fonte de subsistência importante na vida de cada população e tem elo de ligação direta com a pesca. Muitos povos têm suas próprias práticas de pesca. Isso se deve ao fato de ser grande a diversidade cultural entre os povos indígenas. Em seus estudos, Silva (2012, p. 13) destaca como diferenças culturais existentes:

[...] a linguagem, danças, vestimenta, tradições e heranças físicas e biológicas, bem como, a forma como as sociedades indígenas se organizam, conforme a sua cosmovisão e os conceitos de valores moral, crenças, hábitos, religião e a forma como o índio interage com o ambiente.

As técnicas de pesca podem ser realizadas com arco e flecha, lança e armadilhas. Hoje em dia, são usadas ferramentas da sociedade não indígena, tais como: linha e anzol, pouco utilizam a rede de pesca, pois compreendem que ela retira do rio muitas espécies de peixe, que algumas, o povo não consome. Por esse motivo, usa-se a rede só na época do período chuvoso, considerada uma época difícil de conseguir a pesca (ISA, 1996).

Em algumas comunidades, apenas os homens saem para pescar e muitas vezes ficam dias acampados perto de rios e lagoas. A pescaria também pode ser feita por mulheres, ou, realizada em família. Dentre as diversas formas de pesca, uma delas chama a atenção por utilizar o cipó timbó, que é 
uma espécie de planta que tem efeito entorpecedor nos peixes, mas não provoca efeitos no ser humano. Essa, é uma prática milenar entre povos indígenas (TAPIRAPÉ; LEÃO, 2017).

O conhecimento amplo da natureza permitiu aos indígenas explorar esse método de obtenção de alimentos, uma prática que não é realizada indevidamente, pois segue determinadas regras para não prejudicar fortemente os ecossistemas da região onde essa prática é realizada.

Nas palavras de Araújo (1987), "a pesca entre os índios brasileiros constitui uma prática milenar de subsistência muito importante. Há tribos que são ictiófagas (só comem carne de peixe), têm tabu em relação às carnes de outros animais e aves".

Cabe aqui ressaltar, porém, que o povo Ikpeng utiliza outros tipos de carne em sua alimentação, tais como: carne de caça de aves e animais silvestres (macaco, veado, tatu canastra, paca, macaco aranha, entre outros). Isso nos leva a constatar que, mesmo predominando o consumo de peixe na dieta alimentar, o povo lkpeng não é ictiófago e sua cultura influencia diretamente na relação respeitosa com a natureza.

Nas palavras de Araújo (1987), “a pesca com o timbó tem que ser realizada em lagoas rasas. Não se pode usar o timbó em água corrente. No local de entrada da lagoa, por onde os peixes entram e saem, fazem uma espécie de barragem de galhos de árvores". Na época de seca, no período dos meses de agosto e setembro, as lagoas ficam bem rasas e quentes e, por isso, são considerados meses ideais para a pescaria com timbó.

Dutra et al. (2018) relatam que, para iniciar a pesca coletiva com timbó, o povo Tapirapé reúne todas as pessoas da comunidade para entrar em acordo. O cacique marca um outro dia para que as pessoas da comunidade possam procurar um lago que possui bastante peixe. Assim que encontram o lago, o cacique reúne novamente o povo para preparar os materiais e fazer os últimos combinados.

Mesmo descrevendo como ocorre a pesca com o cipó timbó entre os Tapirapé, em seus estudos Tapirapé e Leão (2017) afirmam que esse tipo de pesca coletiva é bastante recorrente entre os povos indígenas, porém, cada etnia tem sua maneira de realizar a pescaria. Os autores defendem que o registro dessa prática é uma maneira de fortalecer as tradições e costumes dos 
indígenas, como também uma forma de aprendizagem para todos sobre os cuidados com a natureza.

\section{PROCEDIMENTOS METODOLÓGICOS}

O presente estudo etnográfico foi realizado na região do médio Xingu, município de Feliz Natal, MT, na principal aldeia da comunidade Ikpeng, denominada de Moygu, onde moram 302 pessoas. Essa pesquisa ocorreu durante o segundo semestre de 2014 e o primeiro semestre de 2015 . Com viés descritivo e exploratório, o estudo apresenta uma abordagem qualitativa.

Segundo Angrosino (2009), as pesquisas etnográficas e observacionais permitem compreender os hábitos de vida de determinado grupo social escolhido para a investigação. Trata-se de uma pesquisa social que utiliza a observação constante e direta nas situações reais em que se manifestam os costumes e condutas das pessoas investigadas, nesse estudo encontram-se relacionadas posturas e atitudes assumidas antes, durante e depois da pesca coletiva com o timbó.

Para empreender esse estudo, realizaram-se, primeiramente, leituras preliminares de artigos referentes à pesca com cipó timbó. Com o intuito de coletar dados, foram entrevistados quatro consultores nativos e registradas as etapas da pescaria por meio de fotografias e registros no diário de bordo. Porém, antes de realizar esses procedimentos de investigação, o projeto de pesquisa foi apresentado ao Conselho da Comunidade Ikpeng, o qual foi devidamente analisado e, posteriormente, aprovado para ser desenvolvido, sendo que o cacique emitiu uma Carta de Anuência.

O critério para seleção desses consultores se deu pelo motivo de serem as pessoas com conhecimentos e experiências sobre 0 assunto. Essas pessoas são consideradas pelo povo Ikpeng como os doutores dos conhecimentos das práticas culturais.

Cada consultor nativo, após saber quais eram os objetivos do estudo, se comprometeu em participar voluntariamente da pesquisa e assinou o Termo de Consentimento Livre e Esclarecido (TCLE), autorizando a utilização e publicação das informações relatadas. Para garantir o anonimato dos sujeitos 
envolvidos na pesquisa, os nomes foram substituídos por Consultor Nativo 1, Consultor Nativo 2 e, assim, sucessivamente.

As entrevistas foram gravadas em áudio, dentro da casa dessas pessoas, posteriormente foram transcritas e analisadas. Todas as informações obtidas nas entrevistas sobre a pesca, foram confirmadas nas observações realizadas nas visitas à campo. As observações do preparo, dos rituais e da própria prática da pesca foram outros instrumentos importantes utilizados para coletar dados, sendo que tudo foi registrado em um diário de bordo.

Durante o andamento da pescaria, os procedimentos foram anotados no diário de bordo. Também ocorreu o registro de imagens para ilustrar a pesca, com o auxílio de uma máquina fotográfica. Além disso, foram realizadas entrevistas com as pessoas que realizaram a pesca (momento em que muitas dúvidas foram sanadas).

Foram realizadas observações sistemáticas com relação à utilização equilibrada dos recursos naturais, ou seja, após a prática da pesca com timbó, retornou-se muitas vezes aos lagos em que ocorreu a pesca coletiva durante sete dias consecutivos para observar aspectos como: período necessário para que a água do lago recuperasse seus aspectos organolépticos normais, tornando-se transparente, se houve a morte de outros animais, além dos peixes coletados.

Para finalizar a redação desse texto, foram realizadas, ainda, revisões e correções levando a criação de novas reflexões que ampliaram a discussão e permitiram a finalização do estudo. A interpretação dos dados coletados ocorreu no âmbito da descrição, o que é indicado por Angrosino (2009) para pesquisas do tipo etnográfica e observacional.

\section{RESULTADOS E DISCUSSÃO}

\subsection{Descrição da Pesca Coletiva com timbó}

Para a pescaria, foi utilizada a planta na fase adulta, pois apresenta maior teor de substância no caule e, dessa maneira, libera líquido em maior quantidade. Segundo relatam os consultores nativos, a pesca com timbó costumeiramente ocorre da seguinte forma: 
Primeiramente a comunidade, ou seja, os homens se reúnem no centro da aldeia para escolher a lagoa ideal para pesca, isso depende muito se há fartura de peixes no lago. A reunião entre os pescadores ocorre uma semana antes, e durante a semana os homens da comunidade preparam as flechas e arcos, e as mulheres rede de pesca e mantimento como polvilho que serão consumidas durante a pescaria. Dois dias antes, os homens vão de casa em casa dando recado para pessoal sobre a realização da pescaria que acontece no dia seguinte, e assim todos ficam cientes (CONSULTOR NATIVO 1, 2014).

Conforme é possível perceber no relato, a cultura da pesca com timbó dos Ikpeng é centrada nos homens, ou seja, o planejamento, as decisões e a maioria das ações envolvidas na pesca coletiva são realizadas por homens. Segue o relato de um consultor nativo sobre alguns aspectos que antecedem a pescaria:

No dia anterior a pescaria, os homens vão ao mato para retirar o timbó, isso ocorre pala parte da manhã, a quantidade retirada depende muito do tamanho do lago, quanto maior o lago maior $\mathrm{e}$ quantidade retirada de timbó (CONSULTOR NATIVO 4, 2014).

Para retirar o cipó do caule das árvores, é preciso muita força, por isso, o trabalho é realizado de maneira coletiva. Enquanto uns ficam retirando, outros transportam os cipós até o acampamento onde serão cortados, conforme o tamanho do braço dos homens. Depois é amarrado com embira ${ }^{3}$. Ele deve ser transportado no mesmo dia para a lagoa.

Pela parte da manhã, os homens cortam caules de árvores para bater no timbó, seguindo também, como referência, a medida do braço. Depois que todos chegam ao lago, o pajé começa a cantar e rezar para que haja fartura de peixe, e só depois que os jovens começam a bater timbó de maneira bem organizada, ou seja, ficam lado a lado. Esta constatação referente a organização e a coletividade entre os Ikpeng é corroborada por outro consultor nativo:

Os homens saem de madrugada para cercar o canal do lago para 0 rio, e dessa forma evitar que os peixes saiam. Para barrar a passagem do canal do rio é utilizada palha de inajá que ficam prezas entre as varinhas. Porém tem muitos lagos quem não tem o canal do rio, ou seja, ela é bem fechada e neste caso não é necessário a utilização da barragem (CONSULTOR NATIVO 2, 2014).

\footnotetext{
${ }^{3}$ Fibra natural extraída da casca de algumas árvores, utilizada como barbante para amarrar alguma coisa.
} 
Percebe-se uma preocupação com o local e mais uma vez fica evidenciado o papel dos homens nesta atividade coletiva. A preocupação evidenciada sobre como proceder durante a pesca para que os peixes sejam capturados também foi evidenciado por outro entrevistado:

Para construir a barragem são cortadas palhas de inajá e as varas compridas, primeiro as varas são fixadas na entrada do canal do rio, as varas ficam lado a lado para que a palha de inajá seja colada entre as varas que depois são firmemente amarradas com embiras (CONSULTOR NATIVO 3, 2014).

As pessoas mais velhas da comunidade estão sempre presentes na pescaria para repassar as regras e ensinamentos para os mais jovens, pois a aprendizagem indígena é baseada na oralidade e prática, só se aprende fazendo, só se aprende observando. Esse aspecto confirma o pensamento de Silva (2012) e de Tapirapé e Leão (2017) de que as tradições, crenças e valores morais são muito respeitados pelos povos indígenas e geralmente relacionadas com a maneira de interação com a natureza.

Os homens ficam batendo o timbó e sujando a água, retirando o máximo possível da substância presente na planta, por aproximadamente uma ou duas horas, e só param quando acabam com todo estoque de timbó, ou quando começam a morrer os primeiros peixes. De maneira simular essa pesca também acontece com os indígenas da etnia Tapirapé (DUTRA et al., 2018; TAPIRAPÉ; LEÃO, 2017).

Segundo Consultor Nativo 1 (2014):

É necessário que os homens que estão batendo timbó durante a pesca, sujam muita a água com a lama que tem na profundidade dos lagos, pois isso ajuda na captura dos peixes, pois quanto mais se suja a água, mais rápido os peixes morrem, porém se os rapazes não sujarem bem a água os peixes não morrem, pois a sujeira do lago pela lama do fundo do rio que contribui e muito para morte dos peixes. Por isso que não pescamos nos lagos que não tenha lama no fundo do rio, ou seja, lagos que tenham só areia.

Complementando essas informações, o Consultor Nativo 3 (2015) relatou:

O cipó timbó não tem a mesma eficácia quando não se suja a água com a lama, os peixes de grande porte não morrem, somente peixes pequenos, pois a lama ajuda a deixar os peixes sem direção. Com água suja, os peixes vêm até a superfície do lago e, desta maneira, são facilmente capturados. 
Outro fator que determina a paralisia rápida dos peixes é a temperatura da água, que favorece na dissolução das substâncias liberadas pelo cipó. Numa lagoa pequena, isso ocorre meia hora depois da batida do timbó, mas, nos lagos grandes, a reação da substância no organismo dos peixes de pequeno porte ocorre duas horas depois

A comunidade recolhe tudo que é possível pegar, e para isso, são usados arco e flechas pelos homens e crianças, para matar peixes de grande porte e também os que ficam muito distante. Já as mulheres usam puxá para pegar peixes de pequeno porte. Muitas famílias passam a noite inteira no lago para poder pegar peixe à noite.

Não se pode afirmar que a comunidade consiga capturar todo o pescado existente no habitat daquele lago, pois muitos peixes afundam e, quando emergem para superfície do lago, já se encontram em estado de decomposição, mas a comunidade se esforça para capturar o máximo possível. "Toda a comunidade participa dessa atividade, homens, mulheres e crianças. Cada família pega o peixe para sua casa. Quando o peixe é bem moqueado ${ }^{5}$, a família consegue manter os peixes por até uma semana" (CONSULTOR NATIVO 1, 2014). Esse procedimento vem ao encontro dos escritos de Taffarel (2010), que em sua dissertação afirmou que as práticas sustentáveis e o cuidado com a natureza são observados a muito tempo entre os lkpeng.

Na visão desse povo, o cipó timbó-açu não é prejudicial à saúde do homem, mesmo consumindo os peixes em grande quantidade. Os consultores nativos não relatam nenhum envenenamento por ação das substâncias liberadas pelo timbó, no entanto, elas podem ser maléficas quando ingeridas, em contato com os olhos ou utilizadas inadequadamente.

Os Ikpeng acreditam que o timbó age no organismo do peixe. Os consultores nativos afirmam que os peixes bebem da água do lago, dessa forma, consumem a substância da planta, levando-os à morte. Também prejudica a visão dos peixes, por isso, os peixes, quando morrem, ficam com olhos bem inchados (CONSULTOR NATIVO 2, 2014).

\footnotetext{
${ }^{4}$ Uma espécie de rede coletora.

${ }^{5}$ Uma técnica de conservação do alimento similar a defumação.
} 


\section{OBSERVAÇÕES REALIZADAS NO ACOMPANHAMENTO DA PESCARIA COLETIVA}

Ao acompanhar a pescaria da comunidade, em duas lagoas da região, pode-se perceber e comprovar: o tempo que o timbó leva para reagir no organismo dos peixes, quais peixes morrem primeiro e a quantidade de timbó utilizada na pescaria. Percebeu-se também o comportamento da comunidade na pescaria e comparar o relato dos consultores nativos entre a pesca no passado e como ela ocorre nos dias de hoje.

No dia 25 de setembro de 2014, quinta-feira, pela manhã, os homens se reuniram no centro da aldeia para escolher o local da retirada do timbó e a quantidade, conforme o tamanho do lago. Este encontro pode ser observado na Figura 1.

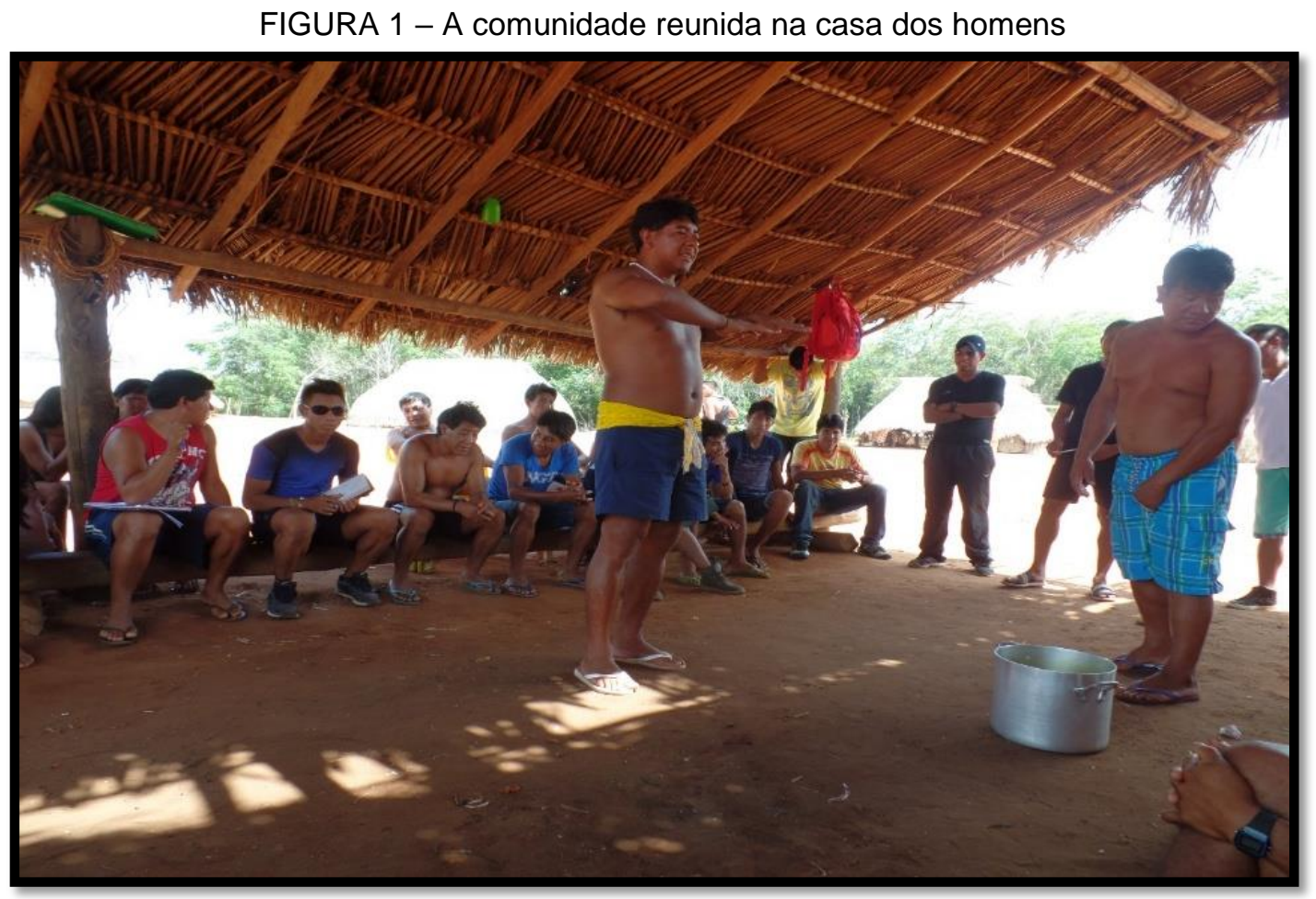

Fonte: Acervo pessoal do autor indígena (2014).

No dia 26 de setembro de 2014, sexta-feira, pela parte da manhã, ocorreu o deslocamento para cortar timbó na outra aldeia Ikpeng, distante a 2 $\mathrm{km}$ da aldeia principal. Chegando ao local onde se encontravam os timbós, o homem mais velho orientou os jovens sobre as regras de comportamento durante a pesca. 
O manejo da planta, cipó timbó, é realizado com muito cuidado, ou seja, tem tempo certo de retirada da planta, não se pode retirar toda planta no mesmo local, anualmente, para que não seja extinta. Pensando nisso, o lugar da retirada da planta é mapeado no entorno da aldeia. Na aldeia lkpeng, existem muitos locais que apresentam maior quantidade dessa planta, considerada eficaz na pescaria, e com ação bem rápida.

Para manejo dessa planta, a comunidade retira de forma consciente apenas plantas adultas, sendo que as plantas em fase de crescimento não podem ser cortadas. Um fato marcante na preservação do cipó timbó-açu é a questão do rodizio do local de retirada, se a comunidade retira de determinado local durante um ano, no ano seguinte, não se pode mais utilizar timbó dessa região, promovendo à planta condições de se recuperar, então, a comunidade utiliza de outra região.

Retirado o timbó dos galhos das árvores, alguns já começaram a cortar em pedaços, conforme o comprimento do braço, enquanto outro grupo foi à procura de embira para amarrar o timbó. Retirada a embira, os jovens começaram a amarração do timbó, seguindo a orientação do homem mais velho. O transporte é realizado no dia seguinte. Nas Figuras 2, 3 e 4, podemos observar os homens cortando, amarrando e transportando o timbó.



Fonte: Acervo pessoal do autor indígena (2014). 


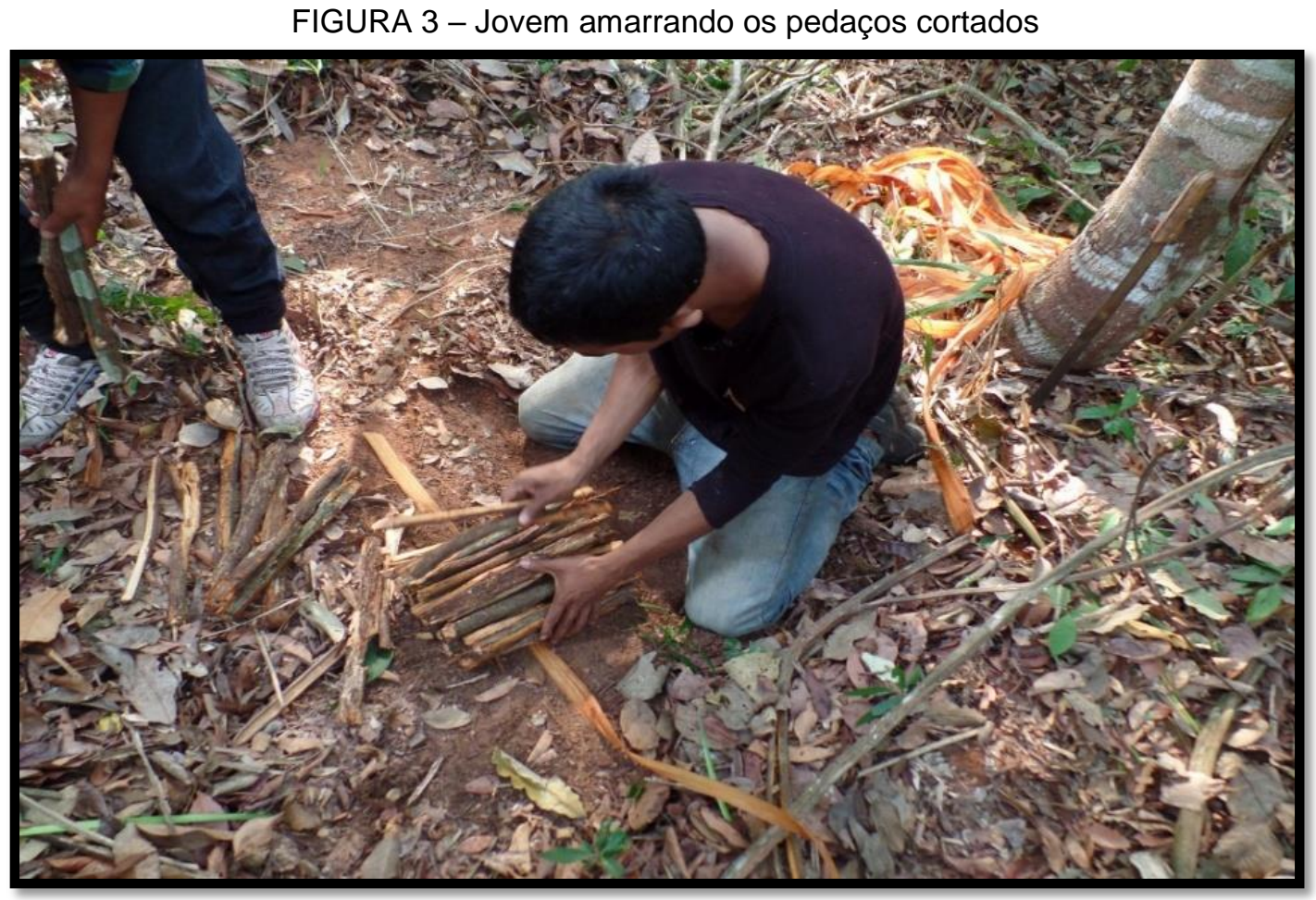

Fonte: Acervo pessoal do autor indígena (2014).

FIGURA 4 - Transportando o timbó



Fonte: Acervo pessoal do autor indígena (2014).

Mais de 110 pedaços de timbó foram amarrados, sendo a maioria deles retirados dos galhos das árvores tinha mais de $10 \mathrm{~m}$ de comprimento, porém, 
as partes finas não são utilizadas. Para um feixe de timbó amarrado, são utilizados 15 pedaços de cipó.

Para transportar o timbó, os homens os amarram em feixes contendo 10 unidades (pedaços), que são carregadas nas costas até o barco e depois são transportados para a lagoa do kotxi egun (lagoa do piau) no mesmo dia. A lagoa tem o comprimento de aproximadamente $200 \mathrm{~m}$, com largura de 40 metros, aproximadamente.

A segunda pesca ocorreu na lagoa de peixe cachorra (wawi egun) que é maior que a lagoa da primeira pescaria, pois possui um comprimento de 250 $\mathrm{m}$ e largura de $60 \mathrm{~m}$ aproximadamente e 3 metros de profundidade.

A Figura 5 apresenta, a quantidade de cipó necessária para a realização desta prática coletiva em um lago com as dimensões especificadas anteriormente.

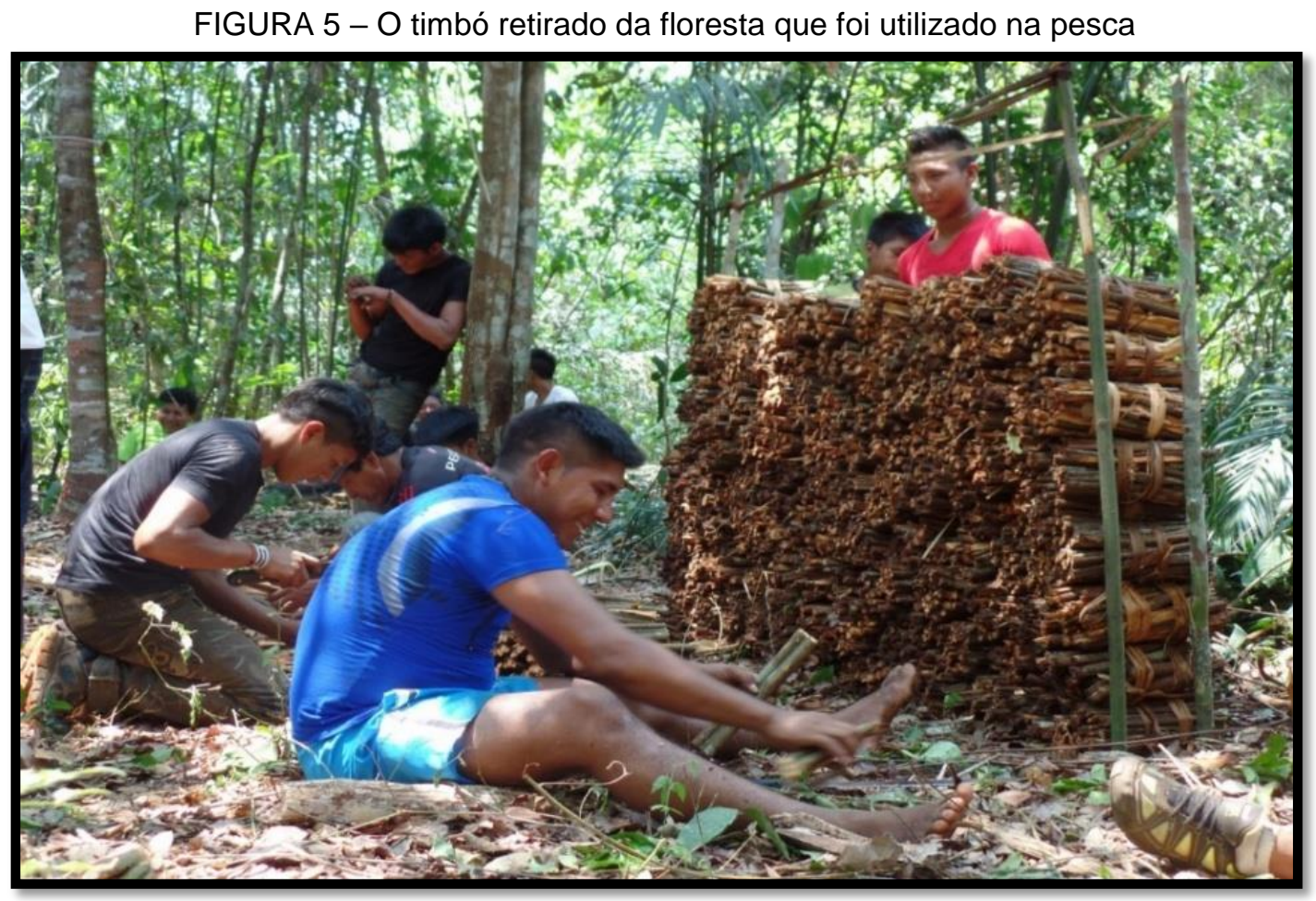

Fonte: Acervo pessoal do autor indígena (2014).

Às $9 \mathrm{~h}$, os homens entram no lago, cada um com três timbós. Mais de 25 pessoas, entre jovens e algumas crianças, bateram timbó. Porém, antes do início da atividade o homem mais velho da comunidade, Kampot Ikpeng de 80 anos, cantou a seguinte música para pedir fartura de peixes durante a pescaria: 
Tugu tapyametket. Tapkalu tapyametket. Wot anungkunangmo. Yotoro anungkunangmo ukmanopyam. Anumko anumko anumko ara. Anumko anumko anumko ara. Tugu tapyametket. Tapkalu tapyametket. Wot anungkunangmo. Yotoro anungkunangmo ukmanopyam. Anumko anumko anumko ara. Anumko anumko anumko ara. Kukukukukuku!!! (KAMPOT IKPENG, 2014).

O canto supracitado é realizado antes de toda pescaria que os Ikpeng realizam com timbó. Nessa letra é solicitado aos donos espirituais da natureza que a pesca seja farta, que haja muitos jiraus para moquear o pescado, que a lenha não dê conta de assar tantos peixes que serão pescados, que nada de ruim aconteça aos pescadores e aos seus filhos durante a pesca, que todos tenham uma boa pescaria. Só depois desse cântico é que os homens comeram a bater o timbó, dispostos em fileira, lado ao lado. A Figura 6 ilustra a forma de organização desse movimento.

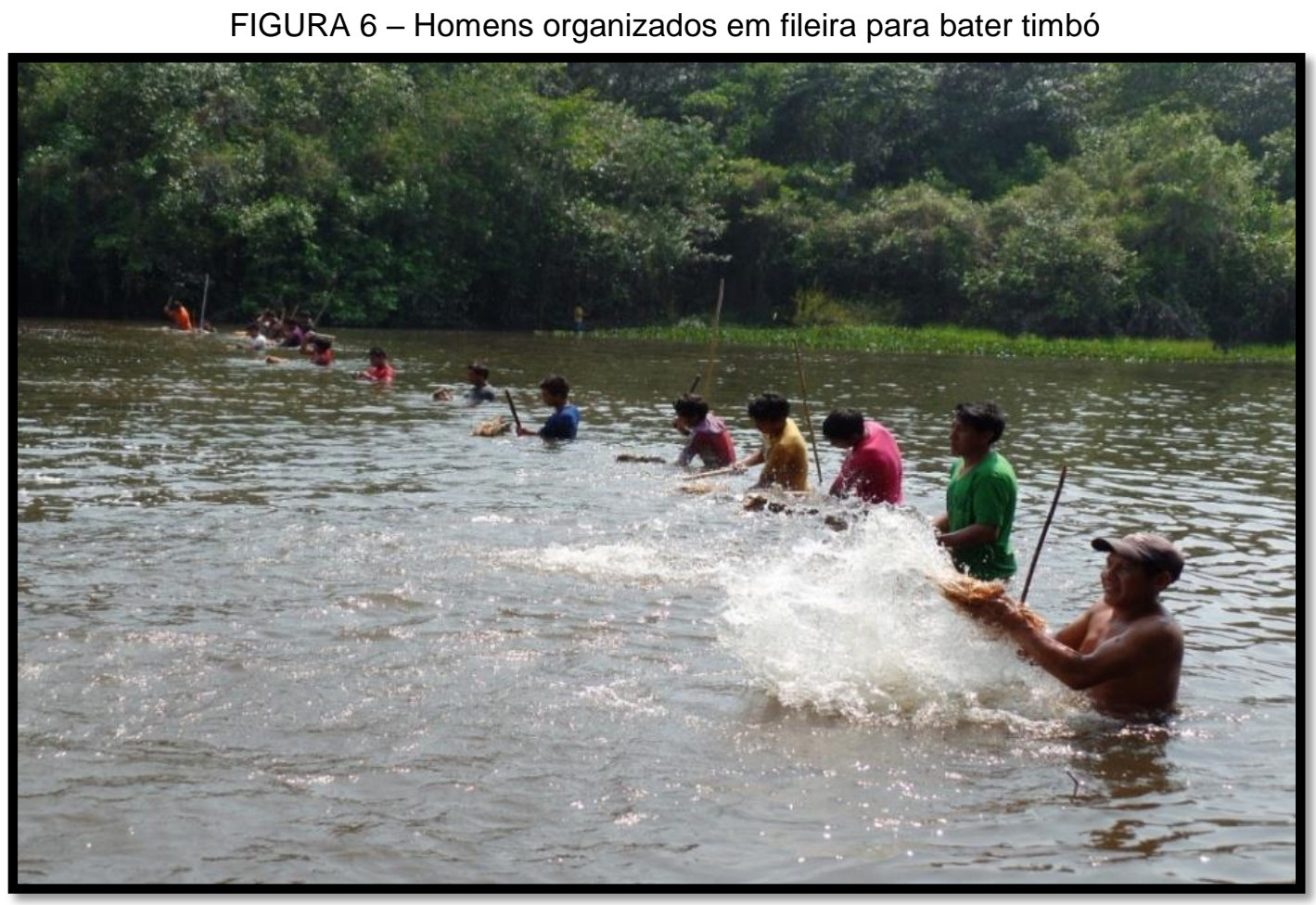

Fonte: Acervo pessoal do autor indígena (2014).

Primeiro sujam o lago realizando movimentos com os pés na lama localizada no fundo, depois começam a bater o timbó com pedaços de madeira fina e pesada, que promovem a retirada da substância. Esse movimento é 
repetido várias vezes na superfície do lago, ou seja, é realizado um movimento de ida e volta às margens daquele lago para acompanhar o efeito da pesca.

Os participantes são divididos em dois grupos, cada um se posiciona em uma margem do lago, ficam batendo o timbó das $9 \mathrm{~h}$ até as $12 \mathrm{~h}$, de modo ininterrupto. Após $2 \mathrm{~h}$ percorridas (por volta das $11 \mathrm{~h}$ ) começaram a morrer os primeiros peixes: Kamtak (Bryconops cf. caudomaculatus), Alapaya (Acestrorhynchus microlepis), Mïtxetko (voadeirinhas), peixe cachorra e pacus. Percebe-se que estas espécies são as primeiras a sentir os efeitos do contato com as substâncias tóxicas do timbó.

A Figura 7 mostra a interação do povo, momento em que homens e mulheres participam.

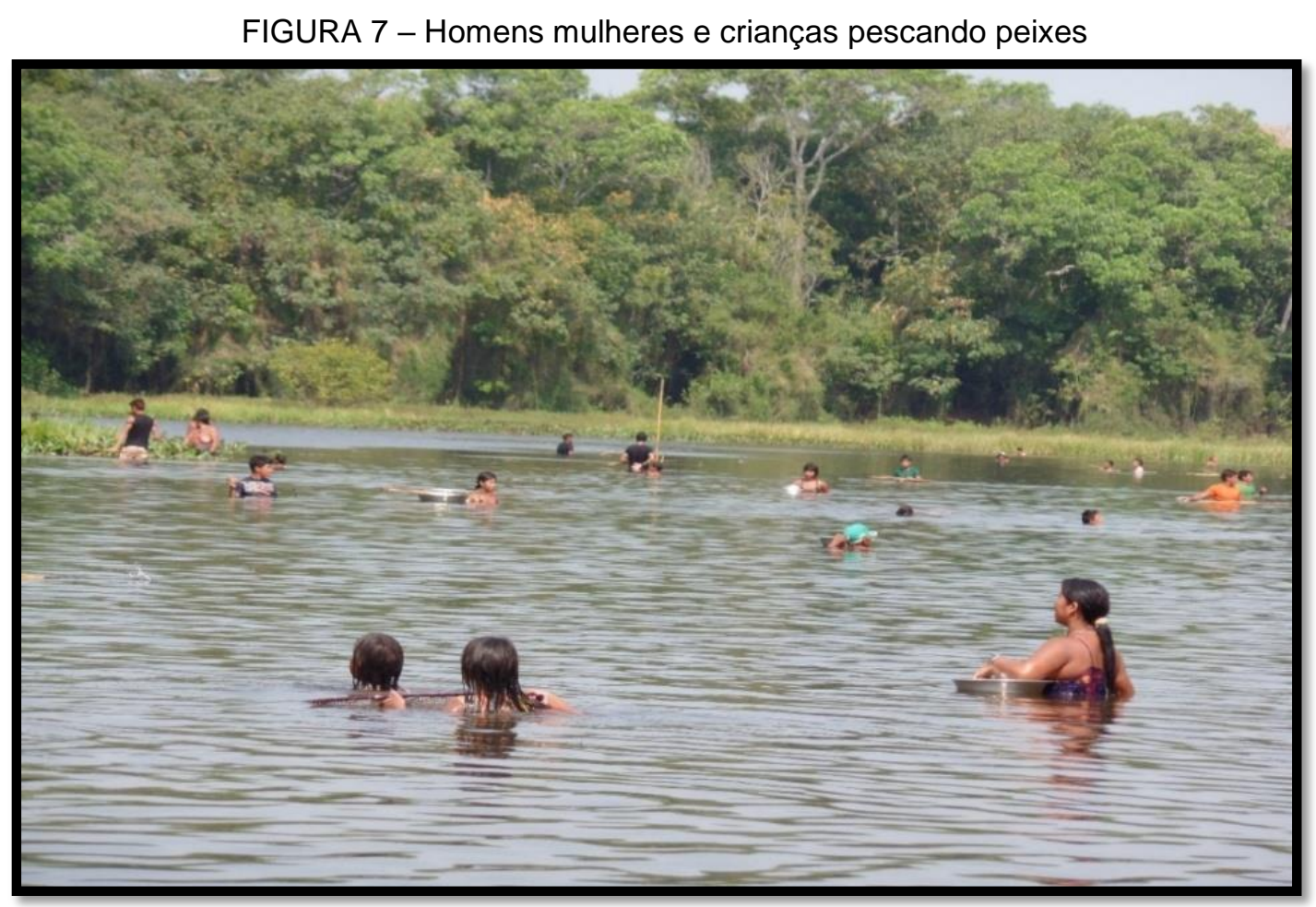

Fonte: Acervo pessoal do autor indígena (2014).

Depois de $4 \mathrm{~h}$, os peixes que possuem hábito de ficar bem no fundo do rio, começaram a morrer: cará, piau, tucunarés, powruk (Aequidens tetramerus), pintado (Pseudoplatystoma corruscans), jacundá (Crenicichla cincta), kaptukalak (Caenotropus cf. schizodon), pitpirak (Curimatella meyeri) e poma (Chalceus guaporensis). Esses peixes mais resistentes são os que atingem os maiores tamanhos. 
Ao anoitecer, muitas famílias dormem na lagoa, assim, jovens e mulheres pescam os peixes com lanterna, usando arco e flecha, e as meninas, rede de pesca. Enquanto os mais velhos cuidavam do jirau ${ }^{6}$, confeccionam uma assadeira feita de embira e pedaços de varinhas. No dia seguinte, todos vão para casa, pois os urubus começam a pousar no lago, e os pajés acreditam que essas aves têm um espirito muito forte que faz mal ao bem estar das pessoas.

Cabe aqui ressaltar que praticamente todos os peixes capturados pela pesca, independentemente do tamanho, são consumidos pela comunidade indígena no mesmo dia ou nos dias subsequentes em que o pescado fica conservado, ou seja, quase não há desperdício. Dessa maneira, os Ikpeng estabelecem uma relação harmoniosa com a natureza, utilizando dela somente o necessário para sobreviver.

Diferente do que muitos pensam, a pesca com timbó exige muito cuidado com os recursos naturais e esse viés ambiental também pode ser explorado ao ensinar ciência naturais. Isso confirma o pensamento de Baniwa (2006) que defende os valiosos ensinamentos dos povos tradicionais para as populações urbanas, principalmente no que tange a vida em harmonia com a natureza.

\section{ENSINAMENTOS DESSA PESCA COLETIVA PARA AS CRIANÇAS}

As crianças Ikpeng aprendem desde pequenas com seus pais, observando, imitando e recebendo orientações para que, futuramente, tenham noção de sobrevivência na natureza, para que possam usufruir dela apenas o necessário para sustentabilidade alimentar e cultural. A educação indígena é baseada na observação, oralidade e realização de práticas, é focada no ensino para a vida.

No aspecto da Educação Ambiental, as crianças participam ativamente da pescaria com cipó timbó, acompanhando seus pais durante a pescaria, ocasião em que aprendem observando os adultos. Elas são curiosas, perguntam tudo que observam, os adultos respondem com tanta delicadeza

\footnotetext{
${ }^{6}$ Espécie de grade confeccionada com varas e gravetos que serve como grelha.
} 
que o ensino se torna o meio social, ou seja, todas as pessoas da comunidade são educadoras.

As crianças acompanham os pais, tios, primos e irmãos na pescaria batendo timbó. As meninas aprendem com a mãe, irmãs, primas e tias a pegar peixes do lago. Também aprendem que não se pode mergulhar no fundo do rio, pois a substância do timbó pode prejudicar a visão. Aprendem a ter cuidados com animais que são considerados perigosos como jacaré e trairão (podem morder), e arraia, que pode ferroar.

$\mathrm{Na}$ Figura 8, podemos observar os ensinamentos sendo transmitidos de pais para filhos.

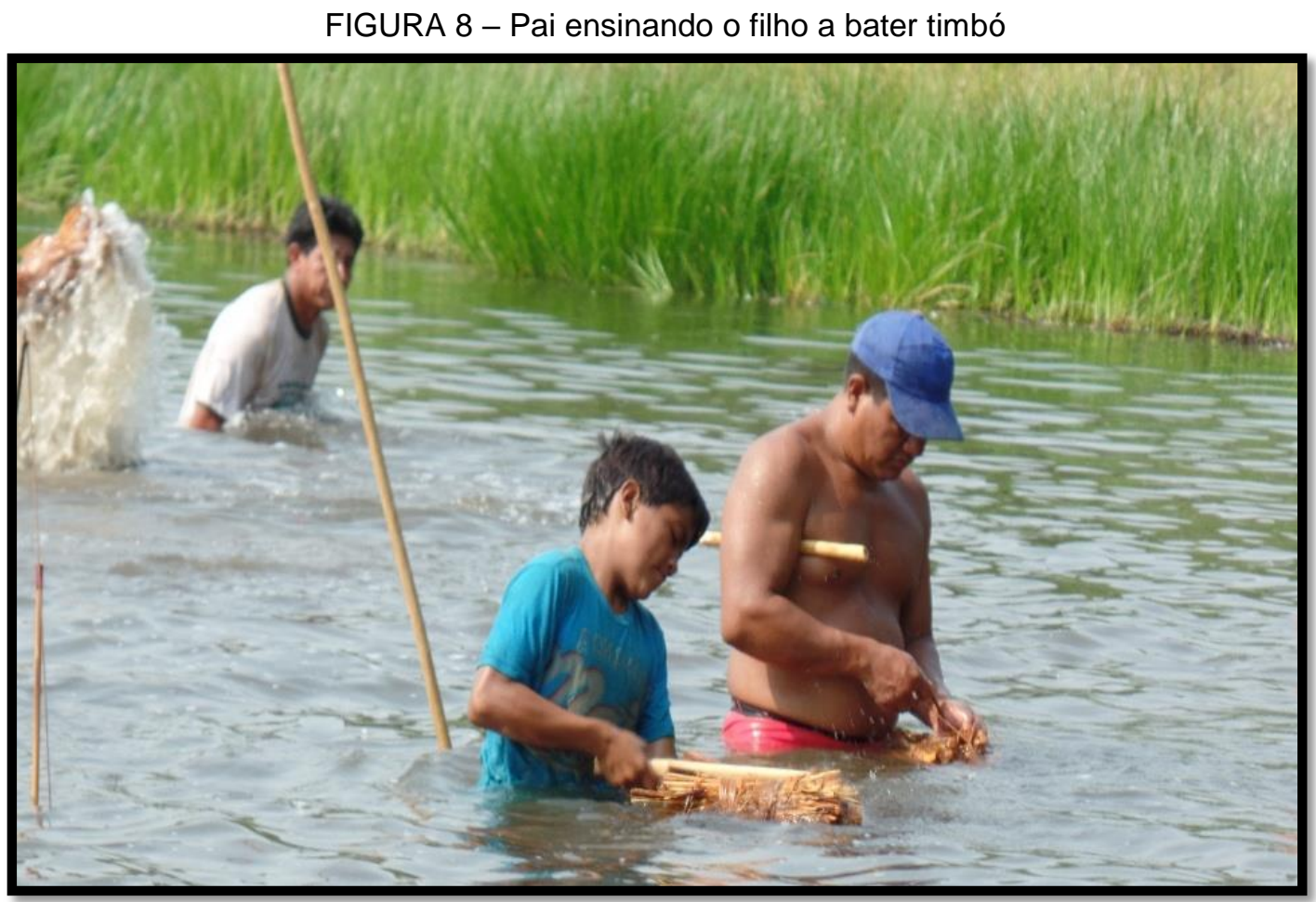

Fonte: Acervo pessoal do autor indígena (2014).

Os meninos, desde crianças, aprendem a manusear arco e flecha, são educados para o uso correto desses objetos, para que não usem de maneira que possam machucar o próximo. Com todos conhecimentos adquiridos com seus familiares, as crianças já são capazes de realizar a prática de pescar com timbó sem auxílio dos adultos, porém, são acompanhadas por irmãos e primos que são adolescentes e já têm noção de como retirar e a forma de cortar timbó, da escolha dos lagos, principalmente, lagos pequenos que não tenham 
presença de arraias, jacarés e peixe elétrico que são muito perigosos durante a pescaria.

As meninas, durante a pescaria, já são capazes de pegar peixe com rede de puxar, são capazes de fazer beiju, elas aprendem a acender o fogo, aprendem que depois de pescaria o fogo deve ser apagado para não prejudicar a floresta. A prática da pesca com rede, realizada pelas meninas, pode ser observada na Figura 9.

FIGURA 9 - Meninas pescando no lago com rede de puxar

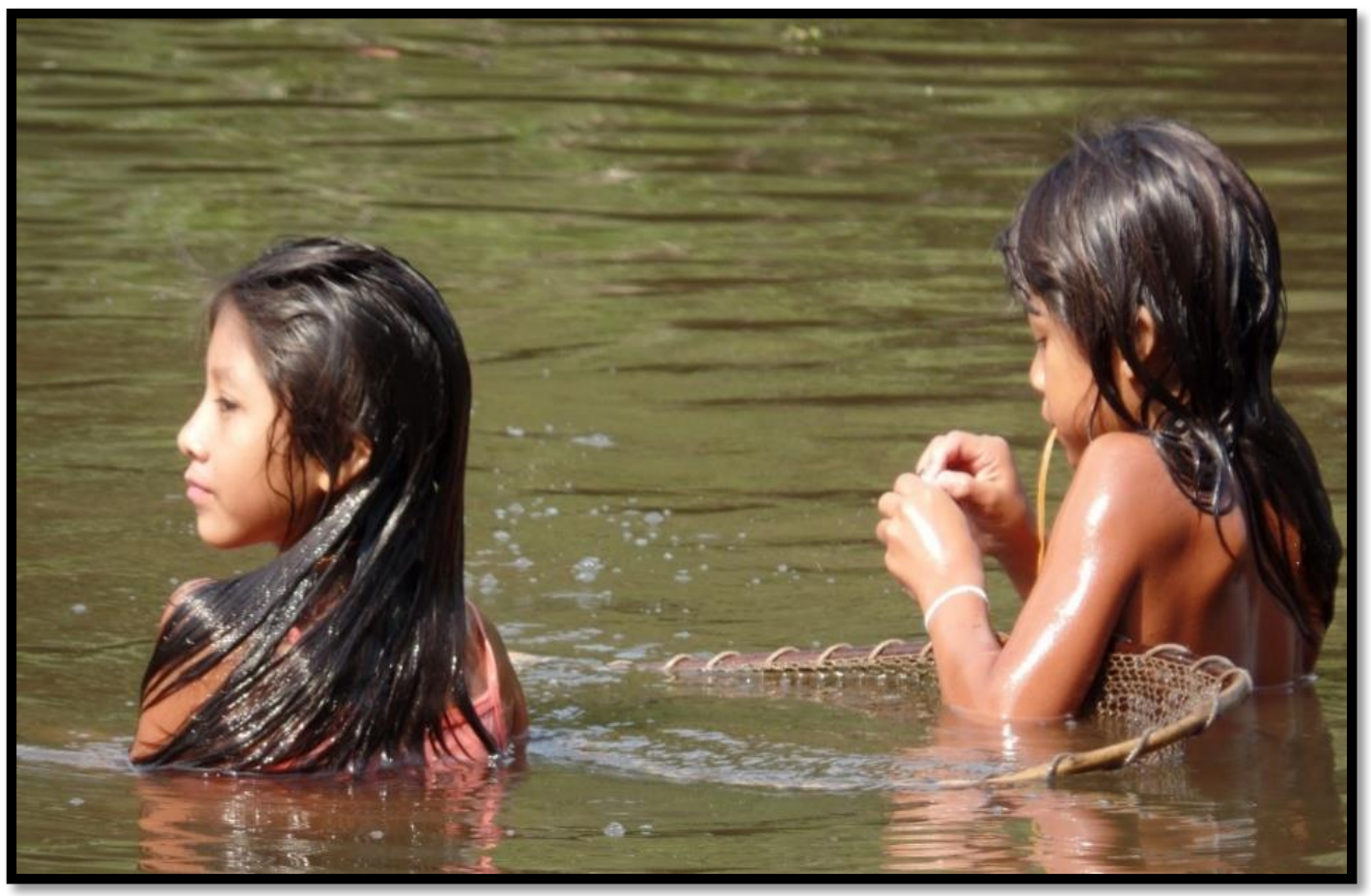

Fonte: Acervo pessoal do autor indígena (2014).

Nessas pescarias, a educação e a solidariedade estão presentes na sociedade Ikpeng e, muitas vezes, se uma criança não consegue pegar o peixe, e algumas pegam em grande quantidade, todos têm direito de compartilhar. A atitude de solidariedade é promovida durante a pescaria.

\section{SUSTENTABILIDADE AMBIENTAL VOLTADA PARA A PESCA COM 0 CIPÓ TIMBÓ}

No passado, as ações que os indígenas realizam para propiciar sua sustentabilidade alimentar, com base no uso de recursos naturais, não prejudicavam o meio ambiente, pois os povos eram nômades e, quando percebiam que os recursos no local estavam se esgotando, mudavam de lugar 
e, dessa forma, a natureza se regenerava. Porém, a realidade hoje é muito distinta daquele tempo.

Hoje, muitos povos indígenas vivem em áreas demarcadas, mesmo assim, apresentam uma preocupação com o manejo dos recursos naturais, e dessa forma, muitas ações são realizadas em forma de rodízio, a fim de não promover o esgotamento dos recursos naturais. Se utilizam uma roça, ou uma pesca no determinado local, deixam o ecossistema num processo de recuperação por um tempo e realizam atividades em outros locais, enquanto o local explorado fica no processo de recuperação (CONSULTOR NATIVO 1, 2014).

O manejo das atividades (pesca com timbó, roças) é um fator de suma importância para os povos indígenas, pois o meio ambiente contribui com a sustentabilidade alimentar, cultural e social. É nessa perspectiva de sustentabilidade que o povo lkpeng, desde suas origens e ainda hoje, vem convivendo e respeitando a natureza (TAFFAREL, 2010).

Para o povo lkpeng, lagoas e peixes têm seus donos espirituais, por esse motivo, não se pesca com o timbó anualmente no mesmo local. Esse respeito com a natureza e com seus donos espirituais também foram confirmados nos estudos de Sá e Silva (2017).

As lagoas grandes que têm maior fartura de peixes como: tucunarés, piau, pacu, piranha, peixe cachorra, curimbatá e outros peixes, são utilizadas no intervalo de dois anos, para que o impacto causado pela ação do timbó seja recuperado. Não se pode bater o timbó anualmente pensando na recuperação da lagoa e sua riqueza, pois se isso acontecer, o dono espiritual dos peixes não vai gostar e mudará de local, levando toda espécie de peixe com ele.

O povo lkpeng tem conhecimento amplo da planta e, por isso, sabe que, mesmo que a substância do timbó entre no rio, não causará danos aos peixes, pois a substância não é muito forte. Ao entrar em contato com rio, ela não apresenta ameaça a nenhuma espécie de peixe que habita o rio. A barragem para fechar a lagoa somente é construída para evitar que os peixes escapem. Depois de bater o timbó, o lago não fica isolado, a barragem é desobstruída no mesmo dia, para que água limpa entre no lago e ajude na sua recuperação e para que os peixes não atingidos pela ação da substância voltem a circular no lago, pois muitos, se escondem debaixo do capim, ou do aguapé. 
Depois que os lagos foram usados na pesca com timbó, foi possível verificar que ocorreu uma recuperação parcial, pois só há uma recuperação total quando ocorrem enchentes. Essa recuperação por meio das enchentes se dá pelo fato dos lagos estarem localizados em região de várzea, e as condições climáticas da região que apresentam seis meses de seca e outros seis de cheia. Percebeu-se uma variação na recuperação dos dois lagos observados, no lago que havia ligação de canal com o rio a recuperação ocorreu em doze dias, e o outro que não tinha canal de ligação com um rio recuperou-se em quatorze dias.

Durante esse estudo, foi possível observar que os ovos dos peixes não são prejudicados, pois depois de duas semanas muitos alevinos foram encontrados nos dois lagos. A Figura 10 mostra a imagem do lago recuperado no qual foi realizada a primeira pesca coletiva.



Fonte: Acervo pessoal do autor indígena (2014).

Outra observação importante verificada durante a pesquisa foi o fato de que mesmo que a substância do timbó entre no rio, ela não é forte o suficiente para prejudicar a vida dos peixes, pois a água é corrente e se espalha rapidamente. 
Pode-se afirmar que as atividades humanas, contínuas e de grande escala são prejudiciais ao meio ambiente. Os estudos de Albuquerque, Leite e Castro (2016) já alertavam sobre as graves consequências da globalização para a natureza e consequentemente para a cultura indígena.

Entretanto, é preciso considerar que os ambientes e ecossistemas em que ocorrem a pesca, como as lagoas por exemplo, são altamente dinâmicos e estão submetidos, constantemente, a eventos naturais (por exemplo, enchentes e tempestades) que reduzem as populações de peixes, e tanto destroem quanto constroem os habitats dos peixes. A dispersão larval permite a recuperação às populações de tais peixes (ROBERTSON; SMITH-VANIZ, 2008).

Atualmente, em torno da aldeia, existem sete lagoas principais. São lagos permanentes, de grande extensão e volume de água, e o uso consciente do meio ambiente é realizado para não afetar radicalmente os ecossistemas, pois, os Ikpeng, realizam o rodizio das lagoas para pescaria com timbó.

Entre os anos de 2013 e 2014, das setes lagoas, só foram realizadas quatro pescarias em lagoas diferentes, as outras três lagoas serão utilizadas em anos seguintes. Dessa maneira, as outras quatro anteriores, com a primeira enchente, poderão se recuperar totalmente. É essa visão consciente das comunidades que mantêm forte suas práticas culturais, pois a pesca com timbó é uma prática milenar, que não deve ser interrompida por motivo de estudos científicos não indígenas, que julgam ser uma prática de crime ambiental,

No ano de 2015, não houve pesca em nenhuma das quatro lagoas de grande porte onde havia ocorrido a pesca nos anos de 2013 e 2014. Esta decisão aconteceu porque os jovens reunidos com os mais velhos, demostraram a preocupação com os ecossistemas da região. Nesse período, as lagoas precisariam se recuperar completamente. O pajé da aldeia também afirmou que os espíritos dos lagos havia pedido para o mesmo avisar o seu povo que no próximo ano iria ofertar muito peixe para comunidade, caso não ocorresse a pesca durante o ano 2015.

A relação de uso dos recursos naturais é consciente, o povo lkpeng vive nessa região há mais de 45 anos e, durante todo esse tempo de pescaria, jamais faltou peixe na dieta alimentar. Nesse período, os lagos continuam ofertando fartura de peixes. Além disso, o cipó timbó ainda existe em grande 
quantidade nas matas e o uso consciente dos recursos naturais é milenar, e é repassado de geração a geração.

Nesse sentido, esses aspectos aqui registrados envolvendo a pesca coletiva com timbó pelo povo Ikpeng podem ser capazes de levar as pessoas a compreender as relações existentes entre meio ambiente e as práticas sociais conforme indica a Resolução № 02/2012. Nesse sentido, as ações ambientais presentes nessa pesca podem ser desenvolvidas em momentos formais ou informais de educação no sentido de ser uma atividade intencional, reflexo dos costumes e da prática social e que está diretamente relacionada com a natureza e com os outros seres humanos (BRASIL, 2012).

\section{CONSIDERAÇÕES FINAIS}

Esse estudo propiciou o registro das etapas do processo de pescaria com cipó timbó, e permitiu constatar que as práticas milenares do povo lkpeng ainda são valorizadas, resistindo à toda influência das tecnologias não indígenas presentes no cotidiano desse povo.

Bom seria se as técnicas utilizadas durante a pesca com timbó, fossem cada vez mais conhecidas e utilizadas pelas gerações futuras. Foi possível constatar que os costumes envolvidos na pescaria fazem parte da história, memórias e cultura do povo, e atualmente são fortemente respeitadas pelas pessoas dessa comunidade.

Pelo estudo realizado, não há como afirmar quais danos ambientais podem ser causados pela ação dessas substâncias presentes na planta, pois há poucos estudos sobre o timbó-açu. Por outro lado, não se pode julgar uma prática milenar dos povos indígenas, tendo pouco conhecimento sobre o processo de como ocorre essa prática coletiva, tampouco, fazer generalizações, geralmente pejorativas, sobre a pesca.

É preciso que o não indígena conheça os hábitos e costumes para compreender a pesca como forma de sobrevivência e, que, por meio dessa prática são retirados de rios e lagos apenas o alimento necessário para esse povo. Há uma grande preocupação, pois a periodicidade que se realiza a pesca com timbó é observada de forma a não comprometer os recursos naturais. 
Pela experiência vivenciada por mais de 40 anos na mesma região, o autor indígena desse texto pode afirmar que jamais faltou oferta de peixes para o consumo na comunidade. Assim como ocorre o rodízio dos lagos, o mesmo método também é usado para o manejo do cipó timbó. De a acordo com os relatos dos consultores nativos, esse método de rodizio é usado de longa data, pelos nossos antepassados, por isso, o equilíbrio ambiental é forte preocupação no cotidiano da comunidade.

Outro fato marcante foi a participação ativa das crianças na pesca. Elas aprendem desde pequenas a prática da pesca com timbó e as regras envolvidas, aprendem que da natureza só se retira o necessário para alimentação da família, aprendem a solidariedade em compartilhar os recursos retirados da natureza com o próximo. As crianças são ensinadas para vida, todos os membros da comunidade são responsáveis pela educação de uma criança.

O estudo poderá contribuir para a compreensão da prática desta pesca coletiva, e também na preservação dos conhecimentos históricos da cultura Ikpeng, para que seja repassada às gerações mais jovens, bem como a futuras gerações. Contribuirá também para a reflexão sobre o manejo e o uso sustentável dos recursos naturais, bem como, da relação equilibrada entre flora e fauna.

Esse estudo permitiu conhecer os aspectos da ciência envolvidos na pesca com timbó-açu, valorizar as culturas e tradições dos Ikpeng com o registro dessa prática permitiu, também, refletir sobre a exploração equilibrada dos recursos que a mãe natureza disponibiliza. 


\section{REFERÊNCIAS}

ALBUQUERQUE, F. E.; LEITE, F. F.; CASTRO, H. de C. Saberes tradicionais e relações interculturais do povo indígena Krahô. Revista COCAR, Belém, v. 10, n. 20, p. 431-455, 2016.

ANGROSINO, M. Etnografia e observação participante. Porto Alegre: Artmed, 2009. (Coleção pesquisa qualitativa).

ARAÚJO, A. M. Brasil: Folclore, Histórias, Costumes e Lendas. 3 ed., 1987. Disponível em: http://infobart.blogspot.com/2009/12/o-estranho-cipo-timbo.html. Acesso em: 8 ago. 2014.

BANIWA, L. dos S. G. O Índio Brasileiro: o que você precisa saber sobre os povos indígenas no Brasil de hoje. Coleção educação para todos. Brasília: Edições MEC/Unesco, 2006.

BARBOSA, A. R.; MENDES, M.; GOMES, M. H.; RIBEIRO NETO, L. J. Aspectos de sustentabilidade dos sistemas tradicionais dos povos indígenas Paiter Suruí: social, cultural, ambiental e econômico. Tellus (UCDB), v. 17, p. 51-70, 2017.

BRASIL. Resolução n. 2, de 15 de junho de 2012. Estabelece as Diretrizes Curriculares Nacionais para a Educação Ambiental. Diário Oficial da União, Brasília, n. 116, seção 1, p. 70, 18 jun. 2012.

DIEGUES, C. A.; VIEIRA, S. R.; CAPEZZUTO, V. A.; FRANCISCA, S. da F.; FIGOLS, B. A.; ANDRADE, D. Biodiversidades e comunidades tradicionais no Brasil. São Paulo maio de 1999, NUPAUB- USP, PROBIO - MMA, CNPq.

DUTRA, M. M.; LEÃO, M. F.; RAMOS, P. R.; LOPES, T. B.; PAULA, W. S. de; MAIA, G. A. M. Narrativas do Povo Apyãwa: Aspectos históricos, culturais e memória. 1. ed. Uberlândia-MG: Edibrás, 2018.

ISA. Instituto Socioambiental. Povos Indígenas no Brasil:1991-1995. São Paulo, Brasil, ISA, 1996: 871.

IBGE. O Brasil indígena. 2010. Disponível em: http://indigenas.ibge.gov.br/ Acesso em: 21 fev. 2016.

IKPENG. Projeto Político Pedagógico (PPP). Escola Indígena Estadual Central. Feliz Natal-MT, 2010.

ROBERTSON, D. R.; SMITH-VANIZ, W. F. Rotenona: Uma ferramenta essencial, mas demonizada, para a avaliação da diversidade dos peixes marinhos. FORUM BioScience, v. 58, n. 2, p. 165-171, 2008.

SÁ, M. J. R.; SILVA, M. das G. Etnoecologia indígena: saberes e fazeres culturais no cotidiano Tentehar. TELLUS (UCDB), v. 17, p. 91-113, 2017. 
SILVA, M. W. Diversidade cultural dos povos Indígenas. 2012. Disponível em: $\quad$ www.progresso.com.br/opiniao/wilson-matos/diversidade-cultural-dospovos indígenas. Acesso em 13 de agosto de 2014.

TAFFAREL, K. Ritual da tatuagem: Educação Ambiental e prática cultural entre os Ikpeng. Dissertação (Mestrado em Educação). Programa de PósGraduação em Educação da Universidade do Estado de Mato Grosso. Cáceres: $\quad$ UNEMAT, $2010 . \quad$ Disponível em: http://www.unemat.br/prppg/ppgca/teses/2010/07.pdf. Acesso em: 10 ago. 2014.

TAPIRAPE, X.; LEÃO, M. F. A importância da pesca com timbó para o povo indígena Apyãwa (Tapirapé) de Mato Grosso. Destaques Acadêmicos, v. 9, p. 155-167, 2017. 